\title{
A ilha escondida de Reil: córtex insular e sua participação nas respostas emocionais, vícios e tomadas de decisões
}

\author{
Reil's Hidden Island: insular cortex and its role in emotional responses, addictions and decision- \\ making
}

La isla escondida de Reil: corteza insular y su papel en las respuestas emocionales, adicciones y toma de decisiones

Recebido: 13/07/2021 | Revisado: 19/07/2021 | Aceito: 19/07/2021 | Publicado: 26/07/2021

Filipe Augusto Azevedo Caixeta

ORCID: https://orcid.org/0000-0003-4086-1545
Centro Universitário de Patos de Minas, Brasil

E-mail: filipeaac@unipam.edu.br

Annelize Florêncio Rabelo

ORCID: https://orcid.org/0000-0003-2689-7824

Centro Universitário de Patos de Minas, Brasil

E-mail: anne_florencioo@hotmail.com

Bárbara Queiroz de Figueiredo

ORCID: https://orcid.org/0000-0003-1630-4597

Centro Universitário de Patos de Minas, Brasil

E-mail: barbarafigueiredo@unipam.edu.br

Rafaela Alves Fernandes

ORCID: https://orcid.org/0000-0002-0050-0844

Centro Universitário de Patos de Minas, Brasil

E-mail: rafaelaaf@unipam.edu.br

Marcelo Gomes de Almeida

ORCID: https://orcid.org/0000-0002-6297-4383

Universidade Federal de Minas Gerais, Brasil E-mail: marcelomedile@yahoo.com.br

Rúbia Carla Oliveira

ORCID: https://orcid.org/0000-0002-7162-3497

Centro Universitário de Patos de Minas, Brasil E-mail: rubiacoliveira@unipam.edu.br

\begin{abstract}
Resumo
Introdução: Apoiado por estudos recentes de neuroimagem humana, a ínsula está reemergindo comouma importante área do cérebro, não apenas na compreensão fisiológica e homeostática do corpo, mas também em contextos patológicos na pesquisa clínica, implicada em funções cognitivas, afetivas e regulatórias distintas, incluindo consciência interoceptiva, respostas emocionais, processos empáticos, tomadas de decisões e até mesmo catalisadora de comportamentos viciosos. Objetivo: Investigar as funções insulares relacionadas aos comportamentos emocionais, vícios e tomadas de decisões, que são corroborados pela ativação do córtex insular. Metodologia: Trata-se de uma pesquisa descritiva do tipo revisão integrativa da literatura, que busca evidências sobre as funções insulares relacionadas às respostas emocionais, vícios e tomadas de decisões. A pesquisa foi realizada por meio de bases de dados PubMed, MEDLINE, Scielo, CDSR, Google Scholar, BVS e EBSCO, no período de 2003 a 2021. Resultados: $\mathrm{O}$ estudo confirma o papel necessário do córtex insular na resposta emocional e afetiva. Além disso, o córtex insular de usuários de drogas exibe alterações estruturais, e a atividade da ínsula durante a tomada de decisão se correlaciona com a propensão de recaída para consumir drogas. Ademais, estudos de imagem funcional em humanos revelaram ativação da ínsula após o consumo de drogas e desejo, e uma das descobertas mais impressionantes de pacientes com lesões de ínsula é que ela interrompe o vício do tabagismo. Conclusão: A ínsula foi tem uma infinidade de funções, que podem, a princípio, apresentar um quadro um tanto confuso, sendo necessários estudos posteriores que esclareçam esta complexa Ilha escondida de Reil.
\end{abstract}

Palavras-chave: Ínsula; Sistema Nervoso Autônomo; Células de von Economo; Fisiologia.

\section{Abstract}

Introduction: Supported by recent studies of human neuroimaging, the insula is re-emerging as an important area of the brain, not only in the physiological and homeostatic understanding of the body, but also in pathological contexts in clinical research, implicated in distinct cognitive, affective and regulatory functions, including interoceptive awareness, emotional responses, empathetic processes, decision making and even addictive behavior catalyst. 
Objective: To investigate insular functions related to emotional behaviors, addictions and decision-making, which are supported by the activation of the insular cortex. Methodology: This is a descriptive research of the integrative literature review type, which seeks evidence on the insular functions related to emotional responses, addictions and decision-making. The search was carried out using PubMed, MEDLINE, Scielo, CDSR, Google Scholar, BVS and EBSCO databases, from 2003 to 2021. Results: The study confirms the necessary role of the insular cortex in the emotional and affective response. Furthermore, the insular cortex of drug users exhibits structural changes, and the activity of the insula during decision-making correlates with the propensity to relapse to use drugs. Furthermore, functional imaging studies in humans have revealed activation of the insula after drug use and craving, and one of the most striking findings of patients with insula lesions is that it stops smoking addiction. Conclusion: The insula has a multitude of functions, which may, at first, present a somewhat confusing picture, and further studies are needed to clarify this complex hidden Isle of Reil.

Keywords: Insula; Autonomic Nervous System; Von Economo cells; Physiology.

\section{Resumen}

Introducción: con el respaldo de estudios recientes de neuroimagen en humanos, la ínsula está resurgiendo como un área importante del cerebro, no solo en la comprensión fisiológica y homeostática del cuerpo, sino también en contextos patológicos en la investigación clínica, implicada en distintos procesos cognitivos, funciones afectivas y reguladoras, incluida la conciencia interoceptiva, las respuestas emocionales, los procesos empáticos, la toma de decisiones e incluso el catalizador de conductas adictivas. Objetivo: Investigar funciones insulares relacionadas con conductas emocionales, adicciones y toma de decisiones, las cuales son apoyadas por la activación de la corteza insular. Metodología: Se trata de una investigación descriptiva del tipo revisión integradora de la literatura, que busca evidencia sobre las funciones insulares relacionadas con las respuestas emocionales, adicciones y toma de decisiones. La búsqueda se realizó utilizando las bases de datos PubMed, MEDLINE, Scielo, CDSR, Google Scholar, BVS y EBSCO, de 2003 a 2021. Resultados: El estudio confirma el papel necesario de la corteza insular en la respuesta emocional y afectiva. Además, la corteza insular de los consumidores de drogas presenta cambios estructurales y la actividad de la ínsula durante la toma de decisiones se correlaciona con la propensión a recaer en el consumo de drogas. Además, los estudios de imágenes funcionales en humanos han revelado la activación de la ínsula después del consumo de drogas y el deseo compulsivo, y uno de los hallazgos más sorprendentes de los pacientes con lesiones de la ínsula es que detiene la adicción al tabaco. Conclusión: La ínsula tiene una multitud de funciones que, al principio, pueden presentar una imagen algo confusa, y se necesitan más estudios para aclarar esta compleja isla oculta de Reil.

Palabras clave: Insula; Sistema Nervioso Autónomo; Celdas von Economo; Fisiología.

\section{Introdução}

Também conhecida por ilha de Reil, o córtex insular é uma região do cérebro que fica escondida no sulco lateral, entre o lobo temporal e parietal, sendo dividido em duas regiões anatomicamente distintas em ínsula anterior (ou frontal) e ínsula posterior. Está dividido em três áreas principais: a área granular dorsal, a área desgranular central, e a área agranular ventral, bem como apresenta conexões com os núcleos da base, córtex perirrinal, córtex olfatório, giro cingulado, córtex parietal, e outras áreas límbicas importantes, como o hipocampo e a amígdala (Shura et al., 2014). No córtex insular anterior se encontram as células de von Economo (VEN), células existentes somente em mamíferos altamente sociais como grandes primatas, baleias, golfinhos e elefantes. Neurocientistas acreditam que estas células são responsáveis pela evolução do comportamento social nos mamíferos, curiosamente os transtornos citados anteriormente apresentam como característica em comum problemas de cunho social relacionados a atenção aos semelhantes (Singer et al., 2009).

Recentemente, tem havido um surto de interesse no córtex insular humano, com um número crescente de estudos de imagens funcionais identificando a ínsula como uma região central afetada por muitos distúrbios psiquiátricos e neurológicos. Paralelamente, as tecnologias modernas disponíveis para dissecar microcircuitos funcionais em modelos animais, especialmente em roedores, colocaram o córtex insular no radar de neurocientistas interessados em compreender os mecanismos neuronais subjacentes às emoções e ao comportamento motivado. Os estudos de neuroimagem demonstram evidências de que a ínsula está envolvida em quase todo tipo de atividade cerebral que envolva emoções sociais como o sentimento de empatia, percepção gustativa, controle cardíaco e percepção corporal, principalmente a interoceptiva, ou seja, a sensibilidade a variação dos estados internos do corpo como temperatura, dor e movimento nos órgãos internos. Além disso, 
estudos de neuroimagem revelaram ativação da ínsula após o consumo de drogas e desejo, e sugerem um papel duplo do córtex insular no vício: as alterações relacionadas à doença podem promover o uso contínuo de drogas por meio do aumento da percepção do desejo e enfraquecer os processos que impedem o uso contínuo de drogas, como a tomada de decisões e a avaliação das consequências negativas (Gogolla, 2017).

Apesar de sua importância, ainda é escasso o conhecimento sobre o papel das estruturas cerebrais e os mecanismos celulares e moleculares envolvidos em seu processamento e armazenamento. Poucos são os livros de neuroanatomia e neurofisiologia que abordam sobre o córtex insular e, isso não é proposital, haja vista que essa região ainda é pouco compreendida pelos neurocientistas. Hipóteses e teorias sobre as funções da insula são motivo de intenso debate entre a comunidade neurocientífica, e, sob essa perspectiva, o presente estudo tem como objetivo investigar e explanar acerca das funções insulares relacionadas aos comportamentos emocionais, vícios e tomadas de decisões, que são corroborados pela ativação do córtex insular.

\section{Metodologia}

Trata-se de uma pesquisa descritiva do tipo revisão integrativa da literatura, que buscou responder quais as evidências sobre as funções do córtex insular nas respostas emocionais, vícios e tomadas de decisões. A pesquisa foi realizada através do acesso online nas bases de dados National Library of Medicine (PubMed MEDLINE), Scientific Electronic Library Online (Scielo), Cochrane Database of Systematic Reviews (CDSR), Google Scholar, Biblioteca Virtual em Saúde (BVS) e EBSCO Information Services, no mês de julho de 2021.

Para a busca das obras foram utilizadas as palavras-chaves presentes nos descritores em Ciências da Saúde (DeCS): em inglês: "insula"; "autonomic nervous system"; "von economo cells"; "physiology", "functions", "addiction", "feeling", em português: "insula"; "sistema nervoso autônomo"; "células de von ecônomo"; "fisiologia", "funções", "vício", "sentimento", e em espanhol: "insula”; "sistema nervioso autónomo"; "celdas von ecônomo”; "fisiología”, "funciones”, "adicción”, "sentimiento".

Como critérios de inclusão, foram considerados artigos originais, que abordassem o tema pesquisado e permitissem acesso integral ao conteúdo do estudo, publicados no período de 2003 a 2021, em inglês, português e espanhol. O critério de exclusão foi imposto naqueles trabalhos que não estavam em inglês, português ou espanhol, que não tinham passado por processo de Peer-View e que não relacionassem as funções da ínsula relacionada a emoções, comportamentos viciosos e tomadas de decisões.

A estratégia de seleção dos artigos seguiu as seguintes etapas: busca nas bases de dados selecionadas; leitura dos títulos de todos os artigos encontrados e exclusão daqueles que não abordavam o assunto; leitura crítica dos resumos dos artigos e leitura na íntegra dos artigos selecionados nas etapas anteriores. Após leitura criteriosa das publicações, 8 artigos não foram utilizados devido aos critérios de exclusão. Assim, totalizaram-se 26 artigos científicos para a revisão integrativa da literatura, com os descritores apresentados acima. Após esta seleção, filtraram-se por artigos dos últimos dezoito e por artigos em línguas portuguesa, inglesa e espanhola.

\section{Resultados e Discussão}

Após a seleção dos artigos por meio dos critérios de inclusão e de exclusão, elaborou-se uma tabela (Tabela 1) contendo as principais informações sobre as funções do córtex insular relacionadas às emoções, comportamentos viciosos e tomadas de decisões. A análise permitiu a percepção de que os estudos sugerem que a ínsula tem papel relevante nesse aspecto. 
Tabela 1: Estudos utilizados na Revisão Integrativa e achados principais.

\begin{tabular}{|c|c|c|}
\hline AUTOR & ANO & PRINCIPAIS ACHADOS \\
\hline Turel, O., et al. & 2020 & $\begin{array}{l}\text { O Transtorno de Jogos na Internet se correlaciona positivamente com a atividade da área } \\
\text { ventral direita e negativamente com atividade no lado dorsolateral direito córtex pré-frontal. A } \\
\text { atividade do córtex insular esquerdo foi maior ao observar indivíduos com privação de } \\
\text { videogame. Por último, houve um maior acoplamento entre a ínsula esquerda. }\end{array}$ \\
\hline $\begin{array}{l}\text { Regner, M. F., } \\
\text { et al. }\end{array}$ & 2019 & $\begin{array}{l}\text { A ínsula fornece a sensação de desejo no cérebro e acredita-se que negocie as sensações de } \\
\text { desejo com controle cognitivo para guiar o comportamento, como fumar ou abster-se } \\
\text { disso. Estudos recentes têm mostrado que o processamento da ínsula é saturável, e que } \\
\text { diferentes funções insulares competem por recursos limitados. }\end{array}$ \\
\hline $\begin{array}{l}\text { Preuschoff, K., } \\
\text { et al. }\end{array}$ & 2008 & $\begin{array}{l}\text { Anatomicamente, a ínsula está bem posicionada para desempenhar um papel integrador na } \\
\text { ligação entre valor afetivo e comportamento adaptativo, pois possui conexões bidirecionais } \\
\text { com inúmeras estruturas implicadas em recompensa e tomada de decisão, incluindo córtex } \\
\text { orbitofrontal, amígdala, giro cingular anterior e nucleus accumbens. }\end{array}$ \\
\hline $\begin{array}{l}\text { Sabin, G. S., et } \\
\text { al. }\end{array}$ & 2009 & $\begin{array}{l}\text { Respostas da amígdala e da ínsula são hiper-reativas às imagens emocionais gerais com } \\
\text { conteúdo emocional negativo, podendo ser duas regiões que participam da neuropatogênese do } \\
\text { transtorno de ansiedade, sendo a reatividade da ínsula ligada a um risco temperamental. }\end{array}$ \\
\hline $\begin{array}{l}\text { Stein, M. B., et } \\
\text { al. }\end{array}$ & 2007 & $\begin{array}{l}\text { Indivíduos propensos à ansiedade tiveram aumento significativamente da amígdala bilateral e } \\
\text { ativação mais alta da ínsula para rostos emocionais. Pontuações mais altas certificam a } \\
\text { avaliação da propensão à ansiedade, que foram associados à maior ativação da amígdala } \\
\text { (predominantemente do lado esquerdo) e a ínsula anterior (bilateral). }\end{array}$ \\
\hline Berntson, et al. & 2010 & $\begin{array}{l}\text { A ínsula tem sido implicada como um componente de redes centrais que atendem a processos } \\
\text { avaliativos e afetivos. Os resultados do estudo apoiam a visão de que o córtex insular pode } \\
\text { desempenhar um amplo papel na integração dos processos afetivos e cognitivos, enquanto a } \\
\text { amígdala pode ter um papel mais seletivo na afetividade. }\end{array}$ \\
\hline Craig, A. D. & 2011 & $\begin{array}{l}\text { A ativação na ínsula anterior se correlaciona diretamente com os sentimentos subjetivos do } \\
\text { corpo e, surpreendentemente, com todos os sentimentos emocionais. A ínsula anterior possui } \\
\text { características adequadas para sustentar a proposta de um modelo de consciência humana e } \\
\text { subjetividade. }\end{array}$ \\
\hline $\begin{array}{l}\text { Caruana, F., et } \\
\text { al. }\end{array}$ & 2011 & $\begin{array}{l}\text { A evidência de um grande número de estudos de imagens cerebrais tem mostrado que, em } \\
\text { humanos, a ínsula e que, especialmente sua parte anterior está envolvida em emoções e } \\
\text { reconhecimento de emoção. Os resultados mostraram que dois comportamentos, um básico } \\
\text { (nojo) e um social (estado afiliativo), foram facilmente provocados por estimulação elétrica de } \\
\text { partes específicas da ínsula. }\end{array}$ \\
\hline Cauda, F., et al. & 2011 & $\begin{array}{l}\text { Os achados documentam duas grandes redes complementares envolvendo a região ventro- } \\
\text { anterior e ínsula dorsal-posterior: uma rede liga a ínsula anterior ao córtex temporal médio e } \\
\text { inferior e córtex cingulado anterior, e está principalmente relacionado às regiões límbicas que } \\
\text { desempenham um papel nos aspectos emocionais; o segundo liga a ínsula médio-posterior ao } \\
\text { pré-motor, sensório-motor, motor suplementar e córtices cingulados posteriores, indicando um } \\
\text { papel para a ínsula na integração sensório-motora. }\end{array}$ \\
\hline $\begin{array}{l}\text { Conteras, M., et } \\
\text { al. }\end{array}$ & 2007 & $\begin{array}{l}\text { Pacientes com danos ao córtex insular podem facilmente parar de fumar. A inativação da ínsula } \\
\text { interoceptiva (corporal) também atenuou os sinais de mal-estar induzido por administração } \\
\text { aguda de lítio. }\end{array}$ \\
\hline $\begin{array}{l}\text { Droutman, V., } \\
\text { et al. }\end{array}$ & 2015 & $\begin{array}{l}\text { Lesões cerebrais que danificam o córtex insular rompem comportamentos de dependência, } \\
\text { sugerindo que a dependência de drogas sensibiliza a ínsula. Estudos de envelhecimento } \\
\text { mostram redução do volume, em usuários de drogas, de matéria cinzenta e atividade na ínsula. }\end{array}$ \\
\hline $\begin{array}{l}\text { Duerden, E. G., } \\
\text { et al. }\end{array}$ & 2013 & $\begin{array}{l}\text { A ativação em resposta a todos os estímulos emocionais ocorreu na ínsula anterior e } \\
\text { intermediária bilateral. Estímulos emocionais positivos foram associados à ativação na ínsula } \\
\text { anterior e média esquerda, enquanto estímulos emocionais negativos, ativados na ínsula } \\
\text { anterior e média bilateral. Ativação em resposta à percepção e a experiência de emoções foi } \\
\text { maior na ínsula anterior bilateral. }\end{array}$ \\
\hline $\begin{array}{l}\text { Ibrahin, C., et } \\
\text { al. }\end{array}$ & 2019 & $\begin{array}{l}\text { A ínsula, uma região do córtex cerebral, é conhecido por estar envolvida em aspectos críticos } \\
\text { subjacentes aos transtornos por uso de substâncias, como interocepção, tomada de decisão, } \\
\text { ansiedade, percepção da dor, cognição, humor, reconhecimento de ameaça e consciência de } \\
\text { impulsos. }\end{array}$ \\
\hline
\end{tabular}




\begin{tabular}{|c|c|c|}
\hline Garavan, H. & 2010 & $\begin{array}{l}\text { O desejo por drogas pode ser um exemplo particular do papel mais amplo da ínsula anterior em } \\
\text { estados de interocepção e sentimento subjetivo semelhantes, por exemplo, a sede e fome. Um } \\
\text { papel importante para o a ínsula no desejo é apoiada por evidências de atividade insular que } \\
\text { mudam com a saciedade. Processos cognitivos envolvendo o papel da ínsula na consciência de } \\
\text { seu próprio comportamento também pode contribuir para o desejo, à medida que evitar o } \\
\text { desejo pode exigir consciência subjetiva. }\end{array}$ \\
\hline $\begin{array}{l}\text { Gasquoine, } P \text {. } \\
\text { G. }\end{array}$ & 2014 & $\begin{array}{l}\text { Dado o papel estabelecido da ínsula na codificação sensorial e aspectos motores da atividade } \\
\text { do sistema autônomo, é esperado que as anormalidades da ínsula devam estar ligadas a } \\
\text { problemas mentais distúrbios que envolvem desregulação emocional. }\end{array}$ \\
\hline $\begin{array}{l}\text { Menon, V., et } \\
\text { al. }\end{array}$ & 2010 & $\begin{array}{l}\text { A ínsula anterior e o córtex cingulado anterior formam uma "rede de saliência" que funciona } \\
\text { para segregar o mais relevante entre os estímulos internos e interpessoais a fim de orientar o } \\
\text { comportamento. Desta forma, com a ínsula como seu centro integral, a rede de saliência auxilia } \\
\text { as regiões cerebrais alvo na geração de respostas comportamentais adequadas para estímulos. }\end{array}$ \\
\hline $\begin{array}{l}\text { Namkung, H., } \\
\text { et al. }\end{array}$ & 2017 & $\begin{array}{l}\text { A ínsula anterior tem um papel central no suporte de estados de sentimento subjetivos, haja } \\
\text { vista que os sinais sensoriais mapeiam o córtex visual primário e, da mesma forma, os sinais } \\
\text { interoceptivos primários são mapeados em sub-regiões específicas na ínsula posterior. É } \\
\text { importante ressaltar que o remapeamento posterior para anterior de sinais interoceptivos } \\
\text { permite percepção consciente da informação interoceptiva. Portanto, a ínsula anterior constitui } \\
\text { a base neural dos estados de sentimento subjetivo. }\end{array}$ \\
\hline $\begin{array}{l}\text { Treadway, } \quad \mathrm{M} . \\
\text { T., et al. }\end{array}$ & 2013 & $\begin{array}{l}\text { A ínsula anterior por si só tem um papel fundamental na subjetividade de sentimentos. A } \\
\text { disfunção da ínsula também está subjacente aos déficits motivacionais, como na dependência } \\
\text { de drogas. }\end{array}$ \\
\hline $\begin{array}{l}\text { Naqvi, N. H., et } \\
\text { al. }\end{array}$ & 2009 & $\begin{array}{l}\text { Evidências recentes indicam que uma estrutura amplamente esquecida, a ínsula, desempenha } \\
\text { um papel crucial nos impulsos conscientes de tomar drogas. A ínsula foi destacada como uma } \\
\text { região que integra estados interoceptivos em sentimentos conscientes e em processos de } \\
\text { tomada de decisão que envolvem risco e recompensa incertos. }\end{array}$ \\
\hline $\begin{array}{l}\text { Naqvi, N. H., et } \\
\text { al. }\end{array}$ & 2007 & $\begin{array}{l}\text { Um questionamento importante é se lesões de ínsula causam uma interrupção da motivação de } \\
\text { comportamentos diferentes de fumar. Essa pesquisa descobriu que nenhum dos pacientes com } \\
\text { danos à ínsula, que interromperam o hábito de fumar, tiveram redução em outros prazeres, } \\
\text { como o de comer. }\end{array}$ \\
\hline $\begin{array}{l}\text { Naqvi, N. H., et } \\
\text { al. }\end{array}$ & 2010 & $\begin{array}{l}\text { A ínsula demonstrou desempenhar um papel nos processos de tomada de decisão que } \\
\text { envolvem dosagem de consequências positivas e negativas, bem como de incertezas. Assim, a } \\
\text { ínsula está envolvida em pesar o positivo e consequências negativas do uso de drogas quando } \\
\text { os indivíduos decidem parar de usar drogas e evitar recaídas. Nessas situações, o indivíduo } \\
\text { lembra tanto do aspecto positivo e das consequências hedônicas do uso de drogas, bem como } \\
\text { as consequências negativas do uso de drogas. }\end{array}$ \\
\hline $\begin{array}{l}\text { Uddin, L. Q., et } \\
\text { al. }\end{array}$ & 2017 & $\begin{array}{l}\text { A ínsula anterior direita está associada com a forma perceptivo-afetiva de empatia, enquanto a } \\
\text { ínsula esquerda está associada a ambas as formas de empatia, afetivo-perceptual e cognitivo- } \\
\text { avaliativa. O papel da ínsula na empatia e cognição social foram confirmadas em estudos de } \\
\text { lesões. }\end{array}$ \\
\hline $\begin{array}{l}\text { Tippett, D. C., } \\
\text { et al. }\end{array}$ & 2018 & $\begin{array}{l}\text { Embora a ativação da ínsula tenha sido frequentemente associada com nojo, há um aumento da } \\
\text { evidência de um papel mais amplo para esta estrutura cerebral em emoções processamento de } \\
\text { informações. A ativação da ínsula também está envolvida na emoção diferencial positiva } \\
\text { versus negativa processamento e na tomada de decisões sobre emoções baseadas na expressão } \\
\text { facial. }\end{array}$ \\
\hline $\begin{array}{l}\text { Paulus, M. P., et } \\
\text { al. }\end{array}$ & 2003 & $\begin{array}{l}\text { A ativação da ínsula serve como um substrato neural crítico para instanciar marcadores } \\
\text { somáticos aversivos que orientam o comportamento de tomada de decisão de risco. }\end{array}$ \\
\hline Singer, T., et al. & 2009 & $\begin{array}{l}\text { As previsões e realizações do corpo e estados afetivos são integrados com previsões e ações de } \\
\text { incerteza, para gerar um sentimento integrado, que é moldado pela preferência de risco } \\
\text { individual e avaliação de risco do contexto. }\end{array}$ \\
\hline $\begin{array}{l}\text { Ullsperger, M., } \\
\text { et al. }\end{array}$ & 2010 & $\begin{array}{l}\text { A ínsula anterior demonstrou ser ativada de forma confiável durante o monitoramento de } \\
\text { desempenho e modulada por consciência de erro. }\end{array}$ \\
\hline
\end{tabular}


A ínsula humana está escondida nas profundezas do hemisfério cerebral pelas camadas frontal e temporal sobrepostas, e consiste em três regiões citoarquitetonicamente distintas: a área agranular anterior, área granular posterior e a zona disgranular de transição, em que cada um tem padrões de coloração histoquímica distintos e conectividade específica. Embora existam vários estudos relatando a conectividade funcional da ínsula com o córtex cingulado, suas relações com outras áreas do cérebro permanecem indefinidas em humanos (Cauda et al., 2011).

\section{- Emoções}

A visão homeostática da integração na ínsula, com base em uma perspectiva anatômica funcional, oferece um modelo plausível para a consciência humana que se encaixa bem com as evidências disponíveis. O papel central da otimização da utilização de energia como uma evolução e pressão adicional podem explicar o padrão de organização da integração insular e sua importância para comportamento humano. Este modelo enfrenta desafios que precisa de uma análise mais aprofundada, mas tem uma notável explicação sob momentos perceptivos, surgimento da música, interação entre emoções positivas e negativas, percepção subjetiva do tempo e equilíbrio emocional (Craig, 2011).

As emoções são estados cerebrais particulares que permitem aos indivíduos lidar com os desafios de seu ambiente físico, e um dos centros envolvidos no processamento de emoções é a ínsula (Caruana et al. 2011). Segundo estudo de Duerden, et al. (2013), realizado por meio de análise de exames de neuroimagem funcionais existentes, a localização espacial e extensão da ativação na ínsula associada com processamento afetivo foram avaliados, sendo quatro resultados principais encontrados: a ativação em resposta a todos os estímulos emocionais ocorreu bilateralmente na ínsula anterior e intermediária, estendendo-se para a posterior; índices de lateralidade revelaram que, na parte posterior, a ínsula do lado esquerdo foi mais ativada do que o direito; estímulos emocionais positivos mostraram dominância do hemisfério esquerdo na ínsula anterior e média, enquanto a ínsula posterior foi ativado bilateralmente. Além disso, participantes masculinos e femininos ativaram o meio esquerdo e direito da ínsula anterior ventral em resposta a todos os estímulos emocionais, homens processaram estímulos emocionais predominantemente na ínsula anterior e média esquerda e na ínsula posterior direita.

Evidências atuais sugerem que a ínsula desempenha um forte papel em sentimentos conscientes, ao antecipar o corpo aos efeitos de eventos emocionais. A ínsula pode, portanto, ser acionada no desejo consciente de fumar, antecipando o prazer das vias respiratórias, efeitos do tabagismo e alívio de efeitos autonômicos intensos da retirada da nicotina. Assim, danos à ínsula podem levar um fumante sentir que seu corpo "esqueceu" o desejo de fumar (Naqvi et al., 2007).

Estudo de Berntson et al. (2010), que avaliou as excitações em resposta a estímulos de imagens em pacientes com lesões na ínsula, comparação aos pacientes do grupo controle, os indivíduos com lesões insulares relataram redução da excitação em resposta para estímulos desagradáveis e agradáveis, bem como atenuação acentuada das classificações de valência. Este padrão não pareceu refletir um viés geral em classificações de excitação, já que as classificações dos grupos de ínsula de estimulação neutra foram semelhantes às avaliações feitas pelos pacientes nos outros grupos. Em vez disso, os pacientes com excitação insular não demonstraram excitação em resposta ao conteúdo da imagem afetiva, e este foi o caso para estímulos agradáveis e desagradáveis.

Estudo de Uddin et al. (2017) descobriu que a ínsula anterior direita estava associada com a forma perceptivo-afetiva de empatia, enquanto a ínsula esquerda estava associada a ambos as formas de empatia afetivo-perceptual e cognitivoavaliativa. Em uma lesão baseada em estudo de mapeamento de sintomas realizado em um grande grupo de pacientes com lesão cerebral traumática, lesões localizadas na ínsula foram associadas às dificuldades da ínsula esquerda em reconhecer emoções desagradáveis e agradáveis. Comparando com relatórios anteriores de um comprometimento específico no reconhecimento de nojo, um estudo consecutivo de 15 pacientes que foram submetidos à ressecção insular (como parte da cirurgia de epilepsia) relataram deficiências significativas em reconhecer expressões faciais de medo, felicidade e surpresa, 
mas não de nojo. Em conjunto, esses estudos iluminam o importante papel da esquerda ínsula anterior no afeto social, como empatia, distinção de emoções primordiais como desgosto, medo e felicidade.

Em estudo de Tippett et al. (2018), abordaram-se técnicas de mapeamento de lesões em indivíduos com acidente vascular cerebral (AVC) agudo do hemisfério direito para investigar lesões associadas ao reconhecimento prejudicado de faces emocionais prototípicas antes reorganização neural significativa, que pode ocorrer durante a recuperação de um acidente vascular cerebral, demonstrando que os traços do hemisfério direito desses pacientes foram significativamente menos precisos para reconhecimento facial emocional para emoções positivas e negativas, bem como que pacientes com lesões da ínsula anterior tinham pontuações significativamente mais baixas do que outros pacientes com AVC no reconhecimento de rostos zangados e felizes. Os resultados fornecem suporte adicional para um papel necessário da amígdala direita e ínsula anterior dentro de uma rede de regiões subjacentes ao reconhecimento de expressões faciais, particularmente aquelas que possuem importância ou relevância motivacional e têm implicações para a prática clínica.

\section{- Vícios}

Estudo de Regner et al. (2019) concluiu que a ínsula é funcionalmente heterogênea, com padrões distintos de conectividade com redes cerebrais em grande escala associadas a numerosas funções e comportamentos. Modelos animais e estudos de lesões humanas sugerem que a ínsula é necessária para a manutenção da nicotina-comportamentos de busca e de consumo de nicotina, bem como outros têm mostrado que a ínsula é um saturável nó de processamento de informações, saturabilidade esta que explicaria como a ínsula funciona em cada estágio do transtorno por uso de nicotina. O desejo durante a retirada pode sobrecarregar o processamento insular para a exclusão de outras funções, como saliência e homeostase neural.

Estudo de Turel et al. (2020) demonstrou que, usando o córtex insular esquerdo como região de interesse, a análise de interação psicofisiológica mostrou aumento da relação entre a ínsula esquerda e o sulco ventral, ao assistir vídeos de League of Legends (LOL), quando comparados ao grupo controle que estava sob privação desse entretenimento, e não na de saciedade, como o primeiro. Além disso, também houve diminuição do acoplamento entre a ínsula esquerda e o córtex pré-frontal dorsolateral esquerdo, ao assistir vídeos de LOL, em comparação com o outro grupo sob privação.

Há evidências de diferenças de interação do neurodesenvolvimento entre sexo e uso de drogas com maior volume pré-frontal em homens com transtorno de uso de álcool em relação a homens controles, e volumes pré-frontais menores em mulheres com transtorno de uso de álcool em relação às mulheres do grupo controle. Muitos estudos, principalmente aqueles que abordam os desejos por comida, têm mostrado que mulheres são mais propensas a desejos alimentares específicos, e, desse modo, é possível que haja diferenças entre os sexos no que diz respeito ao sistema límbico (Garavan, 2010).

O córtex insular, ativado por desequilíbrio homeostático (como a privação de drogas), ou por dicas de recompensa, tem um papel fundamental neste processo de equilíbrio, dado que o vício em substâncias está invariavelmente associado a estados fisiológicos que dão origem a fortes sinais interoceptivos, e envolvem falhas no processo de decisão (por exemplo, escolhendo recompensas imediatas em detrimento de longo prazo consequências negativas). Por isso, não é surpreendente que a ínsula é fortemente envolvida em comportamentos de dependência. O dano cerebral que destrói o IC parece corrigir em pelo menos alguns desses comportamentos viciantes (Droutman et al., 2015).

Com base na função fisiológica da ínsula na motivação, é provável que sentimentos hedônicos evocados podem influenciar a saliência motivacional associada ao uso de drogas, que por sua vez afetariam os comportamentos de tomada de decisão. Déficits motivacionais em indivíduos com anedonia também pode estar relacionada à disfunção da ínsula, haja vista que evidências recentes indicam que alterações estruturais e funcionais da ínsula podem estar associadas a comprometimento baseado no esforço tomada de decisão em indivíduos com anedonia. A nível molecular, a variabilidade nas respostas de 
dopamina, na ínsula bilateral em humanos, foi relatada como correlação com disposição de esforços por recompensas (Treadway et al. 2013).

A busca por drogas e o mal-estar induzem um marcador de ativação neuronal, na ínsula, concluindo que o córtex insular é uma estrutura-chave na percepção das necessidades corporais que direciona comportamentos motivados (Contreras et al. 2007). Outrossim, os estados de sentimentos subjetivos decorrentes da ínsula também podem fornecer uma base para o eu lírico do indivíduo, haja vista que vários investigadores propuseram a ideia de que a representação interoceptiva na ínsula anterior fornece uma consciência do físico lírico como uma entidade de sentimento (senciente), que pode constituir uma base para a individualidade, e até mesmo narcisismo (Namkung et al., 2017).

\section{- Tomada de decisões}

Tomada de decisão, ou seja, selecionar uma ação de um conjunto de alternativas com um resultado incerto, consiste em vários processos de componentes. Um componente particularmente importante da tomada de decisão é assumir riscos, que pode ser definido como a propensão de selecionar uma ação com potencial para um resultado benéfico ou adverso relativamente grande ao longo de uma alteração ação nativa que resulta em um benefício relativamente pequeno. Assumir riscos em si, no entanto, pode ser dividido em vários componentes, incluindo antecipação, recompensa, punição e reprocessamento tardio. (Paulus et al., 2003). Achados clínicos sugerem que um nível apropriado de atividade insular é necessário para fornecer um sinal de alerta para iniciar respostas cerebrais a estímulos salientes, mas este sinal pode ser hiperativo, no caso de ansiedade, ou subativo, como pode ser o caso do autismo (Menon et al. 2010)

A ínsula tem conexões aferentes e eferentes com o córtex medial, orbitofrontal, cingulado anterior e amígdala. Embora a ativação da ínsula tenha sido frequentemente associada com nojo, há um aumento da evidência de um papel mais amplo para esta estrutura cerebral em emoções processamento de informações. A ativação da ínsula também está envolvida na emoção diferencial positiva versus negativa processamento e na tomada de decisões sobre emoções baseadas na expressão facial (Stein et al. 2007). Além disso, a ínsula demonstrou desempenhar um papel nos processos de tomada de decisão que envolvem pesagem consequências positivas e negativas incertas, como em ações hedonistas e imediatistas. A lembrança dessas consequências hedônicas positivas ocorre da mesma forma que acontece quando um indivíduo relembra experiências anteriores com drogas e experiências conscientes aos impulsos (por meio da ação coordenada da ínsula com a amígdala), que pode corroborar a necessidade de usar a droga e, ao mesmo tempo, funcionar na recuperação de consequências negativas do uso de drogas em termos interoceptivos, ou seja, em termos de como as consequências negativas afetarão a integridade do corpo, sobrevivência e manutenção de homeostase. (Naqvi et al. 2010).

Estudos funcionais de neuroimagem têm demonstrado índice volumétrico de massa cinzenta anormal, bem como hiperatividade da ínsula em transtornos alimentares, transtornos de ansiedade, transtornos de humores, autismo, vícios e dores crônicas (Gasquoine, 2014). Ademais, a amígdala e a ínsula estão fortemente interconectadas e acredita-se que desempenhem um forte papel na regulação de respostas econômicas, processamento de experiências afetivas negativas e julgamentos sociais, como a confiabilidade. Além disso, a reatividade da ínsula foi relacionada aos níveis de ansiedade generalizada, mas não para a gravidade da ansiedade social, o que é consistente com os achados anteriores, mostrando que a ansiedade em indivíduos propensos a isso exibe maior reatividade insular para faces emocionais do que grupos normativos para o fator ansiedade (Sabin et al. 2009). A ativação exagerada da ínsula durante a ameaça de choque imprevisível está diretamente relacionada ao baixo controle percebido em indivíduos propensos à ansiedade, apoiando evidências anteriores de que indivíduos propensos à ansiedade podem ter atividade exagerada na ínsula anterior e atividade alterada no córtex cingulado durante a antecipação de eventos aversivos (Ibrahin et al., 2019) 
A atividade insular anterior parece estar intimamente relacionada às respostas autonômicas associadas a erros percebidos conscientemente, embora a causalidade e direções dessas relações ainda precisem ser desvendadas (Ullsperger et al. 2010). Em uma pesquisa associada à neuroeconomia, que explora a base neural da tomada de decisão motivacional, sugeriu-se que a ínsula está envolvida no processamento e aprendizagem de informações sobre risco e incerteza, termo que descreve a incapacidade de prever totalmente um resultado A maioria dos organismos são sensíveis a incertezas, como alguém que pode renunciar a possíveis grandes recompensas em favor de recompensas menores, sendo essas menos incertas (aversão a risco). Estudos de imagem relatam aumento do sinal do córtex insular ao tomar decisões arriscadas (apostas) em comparação à tomada de decisões seguras e em resposta ao aumento da instabilidade, complexidade e ambiguidade (Singer et al., 2009)

Estudo de Preuschoff, et al. (2008) mostrou que a ínsula é ativada sob um contexto de apostas lotéricas, refletindo o risco de predição de erros, sendo ela envolvida em fenômenos relacionados à incerteza, complexidade, ambiguidade e risco, e que precisa ser ativada para codificar informações quantitativas precisas sobre a previsão de risco proveniente de mudanças nos estados corporais. Mais significativamente, os resultados indicaram que o papel da ínsula não se limita a avaliar incertezas, haja vista que as ativações que se correlacionam com erros de previsão de risco sugerem envolvimento insular no risco aprendizagem de previsão. A ínsula também desempenha um papel importante na motivação, particularmente na motivação explícita, que é o desejo consciente ou subjetivo de se envolver em comportamentos. Evidências convergentes implicam que a ínsula codifica valores de incentivo de estímulos, avaliando os estímulos subjetivos e estados sentimentais. (Navqi et al., 2009).

\section{Conclusão}

O córtex insular está envolvido no processamento de dados sensoriais viscerais, motores viscerais, vestibulares, atenção, dor, emoção, informações verbais, motoras, entradas relacionadas à música e alimentação, além de dados gustativos, olfativos, visuais, auditivos e táteis. Dados recentes de neuroimagem, revelaram que o córtex insular estava envolvido em várias doenças neuropsiquiátricas, como transtornos de humor e ansiedade generalizada. Conforme os pesquisadores, a ínsula recebe informações de outras partes do corpo e, acredita-se, ajuda a traduzir esses sinais em impulsos que podem ser sentidos subjetivamente, como a fome, a dor ou a ânsia. Os dados deste estudo indicam um papel seletivo para a região ventromedial, pelo menos dentro do córtex frontal, na regulação da tomada de decisão com probabilidades de resultado conhecidas, e também confirmam o papel necessário do córtex insular na resposta emocional e afetiva.

Além disso, o córtex insular de usuários de drogas exibe alterações estruturais, e a atividade da ínsula durante a tomada de decisão se correlaciona com a propensão de recaída para consumir drogas. Ademais, estudos de imagem funcional em humanos revelaram ativação da ínsula após o consumo de drogas e desejo, e uma das descobertas mais impressionantes de pacientes com lesões de ínsula é que ela interrompe o vício do tabagismo. Desse modo, haja vista a complexidade fisiológica, clínica e cirúrgica do córtex insular, é de suma importância que estudos futuros sobre a ínsula forneçam informações específicas sobre as funções específicas das sub-regiões da ínsula, bem como contabilize os efeitos genéricos do sistema nervoso autônomo relacionados a essa estrutura, embasando-se na relação conhecida entre diferenças individuais na acuidade interoceptiva e experiência emocional, explorando a atividade insular de maneira sinérgica.

\section{Referências}

Berntson, G. G., Norman, G. J., Bechara, A., Bruss, J., Tranel, D. \& Cacioppo, T. (2010). The Insula and Evaluative Processes. Psychological Science. 22 (1), $80-86$.

Caruana, F., Jezzini, A., Fioretti, B. S., Rizzolatti, G. \& Gallese, V. (2011). Emotional and Social Behaviors Elicited by Electrical Stimulation of the Insula in the Macaque Monkey. Current Biology. 21 (1), 195-199. 
Cauda, F., D’Agata, F., Sacco, K., Duca, S., Germiniani, G. \& Vercelli, A. (2011). Functional connectivity of the insula in the resting brain. Neuroimage. 55 $(1), 8-23$.

Cereda, C., Ghika, J., Maeder, P. \& Bogousslavsky, J. (2002). Acidentes vasculares cerebrais restritos ao córtex insular. Neurology. 59 (12). https://doi.org/10.1212/01.WNL.0000038905.75660.BD

Coutreras, M., Ceric, F. \& Torrealba, F. (2007). Inactivation of the Interoceptive Insula Disrupts Drug Craving and Malaise Induced by Lithium. Science. 318 (26), 655-658.

Craig, A. D. (2011). Significance of the insula for the evolution of human awareness of feelings from the body. Ann. N.Y. Acad. Sci. 1225 (1), $72-82$.

Doutrman, V., Read, S. J. \& Bechara, A. (2015). Revisiting the role of the insula in addiction. Trends in Cognitive Sciences. 19 (7), 414-420.

Duerden, E. G., Arsalidou, M., Lee, M. \& Taylor, M. J. (2013). Lateralization of affective processing in the insula. Neuroimage. 78 (1), 159-175.

Garavan, H. (2010). Ínsula e desejo por drogas. Brain Struct Funct. 214 (1), 593-601.

Gasqoine, P. G. (2014). Contributions of the Insula to Cognition and Emotion. Neuropsychol Rev. 24 (2), 77-87.

Gogolla, N. (2017). O córtex insular. Current Biology. 27 (12), 580-586.

Ibrahim, C., Kahana, D. S. R., Pushparaj, A., Musiol, M., Blumberger, D. M., Daskalakis, Z. J., Zangen, A. \& Foll, B. L. (2019). The Insula: a brain simulation target for the treatment of addiction. Frontiers in Pharmacology. 10 (720), 1-18.

Menon, V. \& Uddin, Q. L. (2010). Saliency, switching, attention and control: a network model of insula function. Brain Struct Funct. 214 (1), 655-667.

Namkung, H., Kim, S. H. \& Sawa, A. (2017). The Insula: An Underestimated Brain Area in Clinical Neuroscience, Psychiatry, and Neurology. Trends in Neurosciences. 40 (4), 200-207.

Naqvi, N. H. \& Bechara, A. (2009). The hidden island of addicção: a insula. Trends Neurosci. 32 (1), 56-67.

Naqvi, N. H. \& Bechara, A. (2010). The insula and drug addiction: an interoceptive view of pleasure, urges, and decision-making. Brain Struct Funct. 214 (5), $435-450$.

Naqvi, N. H., Rudrauf, D., Damasio, H. \& Bechara, A. (2007). Science. 315 (26), 531-534.

Paulus, M. P., Rogalsky, C.,Simmons, A., Feinstein, J. S. \& Stein, M. B. (2003). Increased activation in the right insula during risk-taking decision making is related to harm avoidance and neuroticism. Neuroimage. $19(1), 1349-1448$.

Preuschoff, K., Quartz, S. R. \& Bossaerts, P. (2008). Human Insula Activation Reflects Risk Prediction Errors As Well As Risk. The Journal of Neuroscience. $28(11), 2745-2752$

Regner, M. F., Tregellas, J., Kluger, B., Wylie, K., Gowin, J. L. \& Tanabe, J. (2019). A ínsula no transtorno do uso de nicotina: neuroimagem funcional e implicações para a neuromodulação. Neuroscience and Biobehavioral Reviews. 103 (1), 414-424.

Sabin, G. S., Klumpp, H., Angstadt, M., Nathan, B. J. \& Phan, L. K. (2009). Amygdala and insula response to emotional images in patients with generalized social anxiety disorder. J Psychiatry Neurosci. 34 (4), 296-302.

Shura, R. D., Hurley, R. A.; Taber, K. H. (2014). Insular cortex: structural and functional neuroanatomy. The journal of neuropsychiatry and clinical neurosciences. 26 (4). 276-282.

Singer, T., Critchley, HD e Preuschoff, K. (2009). Um papel comum da insula em sentimentos, empatia e incerteza. Trends in Cognitive Sciences, 13 (8), 334 340. doi: $10.1016 /$ j.tics.2009.05.001

Stein, M. B., Simmons, A. N., Feinstein, J. S. \& Paulus, M. P. (2007). Increased Amygdala and Insula Activation During Emotion Processing in AnxietyProne Subjects. Am J Psychiatry.164 (2), 318-327.

Tippett, D. C., Godin, B. R., Oishi, K., Davis, C., Gomez, B. S. Y., Trupe, L. A., Kim, E. H. \& Hillis, A. E. (2018). Impaired Recognition of Emotional Faces after Stroke Involving Right Amygdala or Insula. Semin Speech Lang. 39 (1), 87-100

Treadway, M. T. \& Zald, D. H. (2013). Parsing anhedonia: trans-modelos nacionais de déficits de processamento de recompensa em psicopatologia. Curr. Dir. Psychol. Sci. 22 (1), 244-249.

Turel, O., He, Q., Wei, L. \& Bechara, A. (2020). The role of the insula in internet gaming disorder. Addiction Biology. 26 (2), 1-11. https://doi.org/10.1111/adb.12894

Uddin, L. Q., Nomi, J. S., Seropian, B. H., Ghaziri, J. \& Boucher, O. (2017). Structure and function of the human insula. J Clin Neurophysiol. 34 (4), $300-306$.

Ullsperger, M., Harsay, H. A., Wessel, J. R. \& Ridderinkhof, R. (2010). Conscious perception of errors and its relation to the anterior insula. Brain Struct Funct. 214 (1), 629-643. 